\title{
Guideline adherence in hospital recruited and population based COPD patients
}

Bahareh Jouleh', Marta Erdal ${ }^{2,3^{*}}$, Tomas Mikal Eagan ${ }^{1,2}$, Per Bakke², Amund Gulsvik² and Rune Nielsen ${ }^{1,2}$

\begin{abstract}
Background: Evidence from several studies show poor guideline adherence to COPD treatment, but no such study has been undertaken in Norway. The objectives of this study, was to estimate and compare the guideline adherence to COPD treatment in general population-based and hospital-recruited COPD patients, and find possible predictors of guideline adherence.

Methods: From the prospective, observational EconCOPD-study, we analysed guideline adherence for 90 population-based COPD cases compared to 245 hospital-recruited COPD patients. Overall guideline adherence was defined as correct pharmacological treatment, and influenza vaccination the preceding year, and having received smoking cessation advice. Multivariate logistic regression analysis was performed with the dichotomous outcome overall guideline adherence adjusting for relevant variables.
\end{abstract}

Results: The overall guideline adherence for population-based COPD cases was 6.7\%, significantly lower than the 29. $8 \%$ overall guideline-adherence amongst hospital-recruited COPD patients. Adherence to pharmacological treatment guidelines was 10.0 and 35.5\%, for the two recruitment sources, respectively. GOLD-stage 3 to 4 was associated with significantly better guideline adherence compared to GOLD-stage 2 (OR $(95 \% \mathrm{Cl}) 18.9(8.37,42.7))$. The unadjusted difference between the two recruitment sources was completely explained by degree of airflow obstruction.

Conclusion: Overall guideline adherence was very low for both recruitment sources. We call for increased attention from authorities and healthcare personnel to improve the quality of care given to this patient group.

Keywords: Chronic obstructive pulmonary disease, Guidelines, Adherence, General population

\section{Background}

Chronic obstructive pulmonary disease (COPD) is the third-leading cause of death worldwide [1]. COPD is characterized by chronic symptoms such as shortness of breath and coughing, and by exacerbations that are associated with a faster decline in lung function, increased socioeconomic burden, and mortality [2-7]. There are several known environmental risk factors, like smoking, occupational exposure, and air pollution, which make effective disease prevention possible [8-11]. Correct diagnosis, treatment, and prevention of its exacerbations have the potential of further reducing mortality, morbidity, and disease burden on the society.

\footnotetext{
*Correspondence: marta.erdal@uib.no

${ }^{2}$ Department of Clinical Science, University of Bergen, N-5021 Bergen, Norway

${ }^{3}$ Haukeland, Universitetssjukehus, Laboratoriebygget, Jonas Lies veg 87, 5021

Bergen, Norway

Full list of author information is available at the end of the article
}

There are several treatment options for COPD, and keeping up to date is time-consuming for health care providers. Reliable and regularly updated guidelines are therefore very valuable for clinicians, and help them provide the best care for their patients at any time. Despite available guidelines, these are not consistently implemented [12-20], and hence, their potential for reducing various aspects of disease burden is not taken advantage of $[21,22]$.

The Global Initiative for Chronic Obstructive Lung Disease (GOLD) was launched in 1997 in collaboration with the National institute of Health in USA and the World Health Organisation. GOLD is an international organisation of COPD experts that has developed consensus documents for prevention and management of COPD based on the latest research and evidence. In many countries the GOLD recommendations are perceived as guidelines [23]. 
Evidence from several studies indicate that COPD is substantially under-diagnosed and that there is limited guideline adherence in several countries [12, 24-31]. So far, no systematic study on guideline adherence for COPD has been undertaken in Norway, and none of the mentioned studies from other countries have compared different sampling sources or patient categories. The reason for including both sampling sources was that previous studies have used differing samples and are therefore difficult to compare. Some show results from general practice [24, 27, 30,31], others from hospital-admitted or outpatient participants $[12,25,28$, 29 ], and to our knowledge only one study has reported results from a general population [26]. We wanted to evaluate both sampling sources with the same definitions and multivariate analyses to see if the results differed significantly.

The aim of the current study was to estimate and compare the guideline adherence to COPD treatment in hospital-recruited and population-based COPD patients. In addition, we analysed potential predictors of adherence that can help clinicians improve the care they provide.

\section{Methods}

The EconCOPD study was conducted between March 2005 and August 2006 at Haukeland University Hospital, Bergen, Norway. Details on study design, sampling procedures and data collection have been published previously [32]. The Regional Committee for Medical and Health Research Ethics in Western Norway approved the study (REK Vest case number 252.04), and all participants provided written consent. For the current analyses, we have chosen cross-sectional data from the baseline visit of this study, where a post-bronchodilator spirometry was performed and an interview gathered information about gender, age, smoking habits, education, employment status, comorbidities and medication use.

\section{Study population and design}

The participants were either recruited from a follow-up examination in 2003-2004 of the Hordaland County Respiratory Health Survey, a random and representative sample of the population in Hordaland County in 1985 [33], or from hospital registers from the Department of Thoracic Medicine, Haukeland University Hospital. All participants were current or former smokers of $\geq 2.5$ pack years, and were at least 40 years old. Subjects from the population cohort defined as having COPD were designated as "COPD cases", whereas subjects from the hospital registers were designated as "COPD patients".

Post-bronchodilator spirometry was performed according to ATS-standards [34]. COPD was defined as having a ratio of the forced expiratory volume in one second $\left(\mathrm{FEV}_{1}\right)$ to the forced vital capacity (FVC) $<0.70$ and $\mathrm{FEV}_{1}<80 \%$ of predicted according to age, sex and height [35]. The GOLD-stages were defined according to post-bronchodilator percent of predicted $\mathrm{FEV}_{1}$, stage II being an $\mathrm{FEV}_{1}$ of $50-80 \%$, stage III $30-50 \%$, and stage IV $<30 \%$. Control subjects had both $\mathrm{FEV}_{1}>80 \%$ of predicted and $\mathrm{FEV}_{1} / \mathrm{FVC}>$ 0.7 . As the aim of the current analysis was to evaluate COPD treatment, the control subjects were not included in these specific analyses.

Body mass index (BMI) was defined as weight per squared height $\left(\mathrm{kg} / \mathrm{m}^{2}\right)$. Comorbid conditions were defined by confirmative answers to questions from the Charlson Comorbidity Index [36]. Dyspnoea was defined as grade 1 when experiencing dyspnoea walking up 2 flights of stairs, grade 2 when experiencing dyspnoea walking at level ground, and grade 3 when experiencing dyspnoea while at rest. One pack year of tobacco smoking was smoking 20 cigarettes daily for one year.

\section{Guideline adherence}

The main outcome was guideline adherence in population- and hospital-recruited COPD patients. At the time of data collection, the most recent GOLD document had been published in 2001, with an update in 2004 [37]. Based on the 2004 GOLD document we defined treatment as guideline-adherent when the patient had received smoking cessation advice from a doctor, influenza vaccination the preceding year, and correct pharmacological treatment. The latter was stratified by spirometric grade of obstruction. Correct pharmacological treatment was defined as short-acting muscarinic antagonists or beta agonists (SAMA/ SABA) and long acting muscarinic antagonists or beta agonists (LAMA/LABA) to all (i.e. no underutilization), no inhaled corticosteroids (ICS) to GOLD-II participants and no double medication within same drug group (i.e. no over-utilization). ICS was allowed, but not mandatory in GOLD stage III and IV. Since the recommended pharmacological treatment in stage III and IV was identical, we have analysed these patients together. Considering the robust positive effect of rehabilitation [38, 39], we also analysed rates of receiving rehabilitation in the different sampling sources. Rehabilitation was defined as participation in a rehabilitation programme, or visits to an authorized physiotherapist the last 3 months.

\section{Statistical analyses}

A priori power calculations for the EconCOPD-study were performed based on the main objectives of the study. For the analyses regarding healthcare utilization, a sample size of 95 participants in each COPD-group was 
needed, whilst for the analyses of costs a sample size of 85 participants in each group was needed (aiming for a $\beta$-value of $20 \%$ and significance level of $5 \%$ ).

Bivariate comparison of correlates by participant source and outcomes were performed using KruskalWallis, Chi-Squared, Students T, and Wilcoxon ranksum tests, as appropriate, after evaluating the distribution of the data. For the bivariate comparison of guideline adherence stratified on recruitment source and GOLD-stage, we also performed a trend test ranking GOLD-stage 2 in the population-based sample as number 1, GOLD-stage 2 in the hospital-recruited sample as number 2, GOLD-stage 3-4 in the population-based sample as number 3, and finally, GOLD-stage 3-4 in the hospital-recruited sample as number 4 . Multivariate logistic regression analysis was performed with the dichotomous outcome overall guideline-adherence, adjusting for sampling source, gender, age, education, smoking habits, dyspnoea, doctor's diagnosis of asthma, comorbidities, and $\mathrm{FEV}_{1}$ in percent predicted. Additional multivariate logistic regression analyses were performed to investigate possible predictors for receiving influenza vaccination and rehabilitation. For all analyses, we used Stata SE version 15.1 (StataCorp, Tx, USA).

\section{Results \\ Characteristics}

In total, $90 \mathrm{COPD}$-cases and $245 \mathrm{COPD}$-patients provided complete information at the baseline interview. The response rate was 81 and $79 \%$, respectively, for these two sampling sources. The characteristics and number of prescribed medicines for the populationand hospital- recruited COPD-cases are summarized in Table 1. The hospital recruited COPD-patients were significantly older, had lower BMI, more severe airflow obstruction, more respiratory symptoms and comorbidities, and used more prescribed drugs than the population-based COPD-cases. There was no difference in gender, educational level, or pack years smoked between COPD patients from either of the sampling sources, but there were significantly more current smokers in the population sample than in the hospital sample.

Table 1 Characteristics of hospital- and population-recruited COPD cases in the EconCOPD-study

\begin{tabular}{|c|c|c|}
\hline & Population based COPD cases & Hospital recruited COPD patients \\
\hline $\mathrm{N}$ & 90 & 245 \\
\hline Female sex, \% & 34.4 & 40.0 \\
\hline Age, mean (SD) years & $64.1(10.4)$ & $67.8(9.5)^{* *}$ \\
\hline BMl, mean (SD) kg/m2 & $26.2(4.5)$ & $25.1(5.0) *$ \\
\hline \multicolumn{3}{|l|}{ Education } \\
\hline Primary, \% & 38.9 & 36.7 \\
\hline High School, \% & 38.9 & 48.6 \\
\hline University, \% & 22.2 & 14.7 \\
\hline \multicolumn{3}{|l|}{ Smoking habits } \\
\hline Current smokers, \% & 45.6 & $32.2 *$ \\
\hline Pack year, mean (SD) & $31.1(34.1)$ & $31.8(29.8)$ \\
\hline FEV1, mean (SD) \% & $64.7(14.4)$ & $47.1(17.0)^{* *}$ \\
\hline \multicolumn{3}{|l|}{ GOLD-stage ${ }^{* *}$} \\
\hline GOLD ॥, \% & 84.4 & $48.2 * *$ \\
\hline GOLD III, \% & 10.0 & $33.9^{* *}$ \\
\hline GOLD IV, \% & 5.6 & $18.0^{* *}$ \\
\hline Respiratory symptoms, \% & 74.4 & $95.9^{* *}$ \\
\hline Dyspnoea at level ground \% & 6.7 & $38.1^{* *}$ \\
\hline Cough, \% & 47.8 & $64.5^{* *}$ \\
\hline Phlegm, \% & 48.9 & $62.9 *$ \\
\hline Number of comorbidities, mean (SD), p50 (IQR) & $1.2(1.5), 1(2)$ & $1.9(1.8), 1(3) * *$ \\
\hline Number of prescribed drugs, mean (SD) p50 (IQR) & $3.0(2.9), 2.5(5)$ & $6.3(4.0), 6(6) * *$ \\
\hline
\end{tabular}

${ }^{*}=p$-value $<0,05 .{ }^{* *}=\mathrm{p}$-value $<0,01$ by Kruskal-Wallis and Fishers' exact test. $\mathrm{SD}=$ standard deviation. $\mathrm{p} 50=$ median. $I Q R$ interquartile range Low-threshold dyspnoea $=$ Dyspnoea when walking at normal pace on flat ground, but not at rest

Number of prescribed drugs includes all medication irrespective of cause 
Treatment by recruitment source and GOLD-stages

We found significant differences between COPD cases and COPD patients for all aspects of guideline adherence (Table 2). The overall adherence in the population-based sample was as low as $6.7 \%$ vs $29.8 \%$ for the hospital-recruited sample. Awareness of having COPD, in spite of being informed of having COPD when performing spirometry, varied from $34.4 \%$ in the population-based sample to $85.5 \%$ in the hospital-recruited sample. Adherence to influenza vaccination the preceding 12 months, rehabilitation, smoking cessation advice, and correct pharmacological treatment were all significantly different between the two sampling sources, and consistently higher in the hospital-recruited sample.

Comparing the treatment by GOLD-stage and source of recruitment, the unadjusted analyses only showed significant differences between the cases and patients within GOLD stage 2 (Table 3). The different components of medical treatment for the two samples of GOLD 2-participants differed significantly, with the only two exceptions being ICS and oral b2-agonist. Adherence to advice on influenza vaccination was significantly different between the population-based and the hospital-recruited samples in GOLD stage 2. Only 2 individuals with GOLD stage 2 disease were guideline adherent and had received pulmonary rehabilitation the preceding 3 months, whereas 17 individuals with stage $3 / 4$ disease had received this treatment. We then ranked participants by GOLD-stages and recruitment source in the order: GOLD stage 2 cases, GOLD stage 2 patients, GOLD stage $3 / 4$ cases, GOLD stage $3 / 4$ patients. Trend tests on this ranking revealed that for short-acting and long-acting bronchodilators, combination therapy, overall correct pharmacological treatment, influenza vaccination, rehabilitation, anti-smoking advice, and overall guideline adherence the trend was significant for increasing adherence with increasing rank (results not shown, all $p<0.05)$.

\section{Guideline adherence and predictors}

Neither gender, level of education, respiratory symptoms (with the exception of the dichotomous variable of having dyspnoea or not in the population sample), self-reported asthma, age, BMI, income, pack years, or number of comorbid conditions was associated with guideline-adherence (Tables 4 and 5). Decreasing $\mathrm{FEV}_{1}$ (GOLD stage, $\mathrm{FEV}_{1} \%$ predicted) and increasing number of prescribed drugs were statistically associated with increased adherence.

In bivariate logistic regression analyses on pooled data, several covariates were significantly associated with better guideline adherence (Table 6). Belonging to the hospital sample had an OR (95\% CI) of 5.9 (2.5-14.2) for correct guideline adherence compared to the population sample. Compared to GOLD-stage 2, GOLD-stage 3 and 4 (analysed together) was associated with a substantially higher possibility of receiving correct treatment, OR 23.6 (10.8-51.5), highly significant with $p<0.001$. Being an ex-smoker and having dyspnoea were also both associated with significantly better guideline adherence, OR $2.2(1.3-4.0)$ and 4.3 (2.0-9.3), respectively.

With one exception, all the predictors associated with better guideline adherence in bivariate analyses lost their significance in multivariate regression analyses (Table 6). The exception was GOLD-stage 3 and 4 which gave OR $19.0(8.4-43.0)$ with a $p$-value $<0.001$. Belonging to the hospital sample yielded an OR of 2.4 (0.9-6.5), with $p=0.095$.

Additional file 1: E-Table 1 and Additional file 2: e-Table 2 shows the results of multivariate logistic regression analyses for possible predictors of receiving influenza vaccination and pulmonary rehabilitation. For

Table 2 COPD-treatment in percentage, stratified by recruitment source, results from unadjusted statistical comparison in the EconCOPD-study

\begin{tabular}{lll}
\hline & $\begin{array}{l}\text { Population based } \\
\text { COPD cases } \\
N=90\end{array}$ & $\begin{array}{c}\text { Hospital recruited } \\
\text { COPD patients } \\
N=245\end{array}$ \\
\hline COPD awareness (incl. Chronic bronchitis and emphysema) & 34.4 & $86.5^{*}$ \\
Influenza vaccine preceding 12 months & 34.4 & $70.6^{*}$ \\
Rehabilitation & 5.6 & $16.7^{*}$ \\
Smoking cessation advice (if still smoking) & 82.5 & $96.2^{*}$ \\
Guideline adherent pharmacological treatment & 10.0 & $35.5^{*}$ \\
Overall guideline adherence & 6.7 & $29.8^{*}$ \\
\hline
\end{tabular}

${ }^{*}=p$-value $<0.05$ by Fishers' exact test

Rehabilitation = joined a rehabilitation-program or been in contact with a physiotherapist during the last 3 months

Correct pharmacological treatment = reliever therapy and maintenance therapy and not "overdosed". In addition, no kind of ICS to GOLD2-participants

"Overdosed" = taking same kind of inhaled medicine through 2 different devices

Guideline adherent pharmacological treatment: SAMA/SABA and LAMA/LABA (all). No ICS in GOLD II, no double medication within same drug group

Overall guideline adherence $=$ receiving correct pharmacological treatment and influenza vaccine and smoking cessation advice if still smoking 
Table 3 COPD-treatment in percentage, stratified by recruitment source and GOLD-stage, results from unadjusted statistical comparison in the EconCOPD-study

\begin{tabular}{|c|c|c|c|c|}
\hline & \multicolumn{2}{|l|}{ GOLD 2} & \multicolumn{2}{|l|}{ GOLD 3-4 } \\
\hline & $\begin{array}{l}\text { Population-based } \\
\text { COPD cases } \\
(n=76) \\
\text { Rank } 1\end{array}$ & $\begin{array}{l}\text { Hospital-recruited COPD } \\
\text { patients }(n=118) \\
\text { Rank } 2\end{array}$ & $\begin{array}{l}\text { Population-based } \\
\text { COPD cases } \\
(n=14) \\
\text { Rank } 3\end{array}$ & $\begin{array}{l}\text { Hospital-recruited COPD } \\
\text { patients }(n=127) \\
\text { Rank } 4\end{array}$ \\
\hline SAMA & 9.2 & $39.0 * *$ & 42.9 & 56.7 \\
\hline SABA & 23.7 & $45.8 * *$ & 42.9 & 55.9 \\
\hline LAMA & 1.3 & $15.3 * *$ & 14.3 & 28.4 \\
\hline LABA & 6.6 & $17.8 *$ & 14.3 & 13.4 \\
\hline ICS & 6.6 & 12.7 & 7.1 & 8.7 \\
\hline LABA+ICS in one device & 18.4 & $50.0 * *$ & 57.1 & 71.7 \\
\hline Methylxantines & 0.0 & $13.6 * *$ & 0.0 & 17.3 \\
\hline Oral beta2-agonist & 4.0 & 5.1 & 0.0 & 7.9 \\
\hline Prednisolone or methylprednisolone & 4.0 & $17.0 * *$ & 7.1 & 18.1 \\
\hline -only short period & 2.6 & 5.1 & 7.1 & 8.7 \\
\hline Guideline adherent pharmacological treatment & 4.0 & 7.6 & 42.9 & 61.4 \\
\hline $\begin{array}{l}\text { Self-reported doctors' diagnosis of COPD, } \\
\text { emphysema or chronic bronchitis }\end{array}$ & 27.6 & $80.5^{* *}$ & 71.4 & $92.1^{*}$ \\
\hline Influenza vaccine preceding 12 months & 30.3 & $60.2^{* *}$ & 57.1 & 80.3 \\
\hline Rehabilitation & 5.3 & 11.0 & 7.1 & 22.1 \\
\hline Anti-smoking advice (if still smoking) ${ }^{* * *}$ & 82.9 & 93.6 & 80.0 & 100 \\
\hline Overall guideline adherence & 1.3 & 5.9 & 35.7 & 52.0 \\
\hline $\begin{array}{l}\text { Overall guideline adherence AND rehabilitation, } \\
N(\%)\end{array}$ & $1(1.3)$ & $1(0.9)$ & $0(0)$ & $17(13.4)$ \\
\hline
\end{tabular}

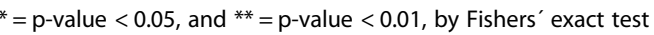

*** lower N (low number of participants)

SAMA $=$ inhaled shortacting muscarinergic agonist. SABA $=$ inhaled shortacting beta2 agonist. $\mathrm{LAMA}=$ inhaled longacting muscarinergic agonist. $\mathrm{LABA}=$ inhaled longacting beta2 agonist. ICS = only ICS (inhaled corticosteroids) in the device

influenza vaccination, we saw that belonging to the hospital sample, being of higher age, and having more severe airflow obstruction were all associated with significantly higher OR, i.e. these variables predicted better vaccination coverage. For participation in rehabilitation, being an ex-smoker was the only significant predictor. Having an airflow obstruction categorized as GOLD-stage 3 and 4 gave a borderline significance with OR (95\% CI) 1.9 (0.9-3.9), and $p$-value 0.08 , implying higher inclusion in rehabilitation programmes for these patients.

\section{Discussion}

We have found that, on average, the overall guideline adherence to COPD treatment for population-based COPD cases was $6.7 \%$, which was significantly lower compared to the $29.8 \%$ overall guideline-adherence amongst hospital-recruited COPD-patients. Adherence to pharmacological treatment guidelines was 10.0 and $35.5 \%$, for the population-based and hospital-recruited participants, respectively. In multivariate regression analyses we found that having GOLD-stage 3 and 4 was associated with significantly better guideline adherence, and a trend of more adherence in hospital treated patients. The grand majority of all participants who still smoked had been given smoking cessation advice. The observed higher rate of current smoking amongst the COPD cases is most likely due to significantly less symptoms in this group compared to the hospital-recruited COPD patients, leading to fewer quitters. Additionally, there were significantly fewer COPD cases that had received smoking cessation advice.

The lack of adherence was significantly lower in the general population, and multivariate regression analyses indicated that the main cause for this was more severe COPD in the hospital-recruited sample. This finding highlights the importance of improving the quality of COPD treatment of milder cases of COPD, that are treated by general practitioners. In Denmark, Lange et al. showed that after implementation of an educational programme on COPD for general practitioners, the quality of care increased significantly with more use of spirometry and more appropriate use of ICS [24]. In Swedish general practice, the management of COPD 
Table 4 Percentage of overall guideline adherence in population based COPD and hospital recruited COPD patients by the categorical variables gender, education, respiratory symptoms and asthma diagnosis

\begin{tabular}{|c|c|c|c|}
\hline & & $\begin{array}{l}\text { Population based } \\
\text { COPD cases } \\
N=90\end{array}$ & $\begin{array}{l}\text { Hospital recruited } \\
\text { COPD patients } \\
N=245\end{array}$ \\
\hline \multirow[t]{2}{*}{$\overline{\text { Sex }}$} & Female & 9.7 & 29.6 \\
\hline & Male & 5.1 & 29.9 \\
\hline \multirow[t]{3}{*}{ Education } & Primary & 8.6 & 28.9 \\
\hline & High school & 5.7 & 27.7 \\
\hline & University & 5.0 & 38.9 \\
\hline \multirow[t]{2}{*}{ Lung function } & GOLD ॥ & $1.3^{*}$ & $5.9^{*}$ \\
\hline & $\begin{array}{l}\text { GOLD III } \\
\text { and IV }\end{array}$ & $35.7^{*}$ & $52.0^{*}$ \\
\hline \multirow{3}{*}{$\begin{array}{l}\text { Respiratory } \\
\text { symptoms }\end{array}$} & Dyspnoea & $14.0^{*}$ & 32.5 \\
\hline & Cough & 9.3 & 29.1 \\
\hline & Phlegm & 4.6 & 28.6 \\
\hline \multirow{2}{*}{$\begin{array}{l}\text { Doctor's } \\
\text { diagnosis of } \\
\text { asthma }\end{array}$} & No & 6.5 & 26.7 \\
\hline & Yes & 7.1 & 32.8 \\
\hline
\end{tabular}

* $=$ p-value $<0.05$ by Fisher's test on intra-group comparison

Guideline adherence $=$ reliever therapy and maintenance therapy and not "overdosed". In addition, no kind of ICS to GOLD2-participants

patients has been proven inadequate [40]. The current study is by design unable to identify the "perpetrator" of poor guideline adherence, as both patients themselves, healthcare practitioners, and effectiveness of available treatment will likely influence adherence. But both health care personnel and the authorities should give this patient group greater attention through increasing the level of knowledge of the disease, and through

Table 5 Mean differences of age, BMl, income, tobacco exposure, $\mathrm{FEV}_{1}$, number of comorbid conditions, and number of drugs in use between guideline adherent and nonadherent COPD subjects, stratified by recruitment source

Population Hospital recruited based COPD COPD patients, cases, mean mean difference difference adherent adherent - nonadherent nonadherent

\begin{tabular}{lll}
\hline Age (years at baseline) & 11.1 & -0.1 \\
$\mathrm{BMI}\left(\mathrm{kg} / \mathrm{m}^{2}\right)$ & -2.3 & -0.4 \\
Income (NOK yearly income) & 401,898 & -9539 \\
Pack years ((cig/day*years smoked)/20) & -3.9 & -0.2 \\
$\begin{array}{l}\mathrm{FEV}_{1} \text { (post-bronchodilator \% of } \\
\text { predicted) }\end{array}$ & $-29.9^{* *}$ & $-16.5^{* *}$ \\
$\begin{array}{l}\text { Number of comorbid conditions } \\
\text { (mean) }\end{array}$ & 0.8 & 0.1 \\
$\begin{array}{l}\text { Number of drugs in use (mean) } \\
\text { la }\end{array}$ & $3.6^{* *}$ & 1.0 \\
\hline
\end{tabular}

${ }^{*}=p$-value $<0.01$ by Mann-Whitney test on intra-group comparison simplification of access to and implementation of treatment guidelines. When performing spirometry, all the participants who appeared to have COPD were given notice about their status. Even so, only $34.4 \%$ of the cases answered that they were aware of having COPD when asked during the baseline interview. There might be several explanations for this, one being the ability of the study doctor or nurse to inform in a manner that made the participants understand their results. And another explanation might be that COPD is a stigmatising disease which the participants wished not to recognize.

The low COPD guideline adherence in our study has also been observed in other countries $[12,16,18,20$, $28-31$ ]. This deficiency does not only imply a precarious treatment of inferior quality for the patients, it can also have juridical consequences for the health personnel responsible for the treatment. By Norwegian law, the reason of failure to adhere to guidelines must be recorded in the patient journal. The current study is the first to demonstrate overall guideline adherence in COPD in Norway. Previous studies have looked at the use of ICS and also other maintenance drugs and medication during acute exacerbations [41-43]. These studies showed over-prescription of ICS to COPD-patients, and that objective diagnostic tests to evaluate if the patients really are having an exacerbation are rarely recommended. The proportion of participants who both received overall guideline adherent treatment and pulmonary rehabilitation was $13 \%$ among the subjects likely to have more severe disease. This is particularly alarming, given the evidence for positive effect of rehabilitation $[38,39]$.

In 2014, the Norwegian Heart and Lung patient organisation performed a survey that showed that amongst the institutions responsible for the education of medical doctors or psychologists, $71 \%$ used COPD guidelines, but only $24 \%$ of the institutions educating nurses and physiotherapists [44]. A structured education of health care personnel on how to implement guidelines is warranted, along with a possible establishment of incentives for the health care personnel who do adhere to the guidelines.

The main strength of this study is the ability to provide overall guideline adherence in both population-based and hospital recruited COPD patients. The observed difference between these sampling sources was completely explained by disease severity. Diagnoses were confirmed by state-of-the-art spirometry, and we have chosen to emphasize clinically significant disease by excluding subjects with FEV1 above $80 \%$ of predicted. Additionally, our study is the first of its kind to be conducted in Norway. Nevertheless, there are some possible limitations that deserve mentioning. The sample size for the population-recruited COPD cases is of borderline magnitude, though this only serves to give more conservative 
Table 6 Bivariate and multivariate logistic regression for guideline adherence (odds ratios (OR), and 95\% Cls in brackets) to COPD treatment in hospital- and population-recruited patients in the EconCOPD-study

\begin{tabular}{|c|c|c|}
\hline & Bivariate & Multivariate \\
\hline Population-based COPD cases & ref & ref \\
\hline Hospital-recruited COPD patients & $5.9^{* *}[2.5,14.2]$ & $2.4^{*}[0.9,6.5]$ \\
\hline \multicolumn{3}{|l|}{ Gender } \\
\hline Male & ref & ref \\
\hline Female & $1.1[0.7,1.9]$ & $1.4[0.7,2.7]$ \\
\hline Age, 10 yrs. increment & $1.2[0.9,1.6]$ & $1.1[0.8,1.6]$ \\
\hline \multicolumn{3}{|l|}{ GOLD-stage } \\
\hline Stage 2 & ref & ref \\
\hline Stage 3 and 4 & $\begin{array}{l}23.6^{* *} \\
{[10.8,51.5]}\end{array}$ & $\begin{array}{l}19.0^{* *} \\
{[8.4,43.0]}\end{array}$ \\
\hline \multicolumn{3}{|l|}{ Smoking status } \\
\hline Current smoker & ref & ref \\
\hline Ex-smoker & $2.2^{* *}[1.3,4.0]$ & $1.4[0.7,2.9]$ \\
\hline \multicolumn{3}{|l|}{ Education } \\
\hline Primary School & ref & ref \\
\hline High School & $1.0[0.6,1.7]$ & $1.3[0.6,2.7]$ \\
\hline University & $1.2[0.6,2.5]$ & $2.0[0.8,5.1]$ \\
\hline \multicolumn{3}{|l|}{ Dyspnoea } \\
\hline No dyspnoea & ref & ref \\
\hline Dyspnoea, any grade & $4.3^{* *}[2.0,9.4]$ & $1.6[0.6,4.3]$ \\
\hline \multicolumn{3}{|l|}{ Doctors diagnosis asthma } \\
\hline No & ref & ref \\
\hline Yes & $1.6^{*}[1.0,2.6]$ & $0.8[0.4,1.6]$ \\
\hline $\begin{array}{l}\text { Number of comorbid conditions } \\
\text { (mean) }\end{array}$ & $1.1[1.0,1.3]$ & $1.0[0.9,1.3]$ \\
\hline$N$ & 335 & 335 \\
\hline
\end{tabular}

results than what might be true for a larger populationbased sample. Further on, the participants were recruited from the city of Bergen in Western Norway and 11 surrounding municipalities, and this might have an influence on the external validity of the study. However, a comparison between national Norwegian survey data and the original cohort from which the EconCOPD-study recruited from, showed no discrepancies [45]. Additionally, we lack information of the role of oxygen as we did not perform arterial blood gas samples. Further, some of those invited to participate did decline the invitation. Analyses were made to evaluate if the non-responders would have changed our results, but there were no significant differences in gender or $\mathrm{FEV}_{1}$ percentage of predicted between non-responders and responders $[45,46]$. Finally, some years have passed by since the data in this study was collected, but the epidemiology of COPD and its disease mechanisms are the same, no major drug groups have been developed since undertaking the EconCOPD-study, and the most effective health care interventions are still smoking cessation, rehabilitation and oxygen supplement on the clinically appropriate indication.

The guideline adherence for treatment of COPD was disappointingly low. This finding should be taken as an encouragement to healthcare practitioners and decision makers, because it highlights that the potential for improvement for these patients is considerable. We need accessible guidelines for healthcare workers, drug devises that facilitates compliance, accessible rehabilitation facilities, and vaccination programmes to ensure that COPD patients are offered the best care available.

\section{Conclusions}

We conclude that COPD patients receive guideline adherent treatment in 6.7 and $29.8 \%$ of the cases from a general population and from a hospital register, respectively, and that the difference between the two samples is explained by grade of airflow obstruction. We call for increased attention from authorities and health care personnel to improve the quality of care given to this patient group.

\section{Additional files}

Additional file 1: Multivariate logistic regression for receiving influenza vaccination (odds ratios (OR), and 95\% Cls in brackets) in hospital- and population-recruited patients in the EconCOPD-study. Table containing ORs (odds ratios) from multivariate regression analysing whether there were any predictors for receiving influenza vaccination. (RTF 64 kb)

Additional file 2: Multivariate logistic regression for participating in pulmonary rehabilitation (odds ratios (OR), and 95\% Cls in brackets) in hospital- and population-recruited patients in the EconCOPD-study. Table containing ORs from multivariate regression analysing whether there were any predictors for participating in pulmonary rehabilitation. (RTF 61 kb)

\section{Abbreviations}

ATS: American Thoracic Society; BMI: Body mass index; Cl: Confidence interval; COPD: Chronic obstructive pulmonary disease; EconCOPD: Economics of COPD-study; FEV 1 : Forced expiratory volume in $1 \mathrm{~s}$; FVC: Forced vital capacity; GOLD: Global initiative for chronic obstructive lung disease; ICS: Inhaled corticosteroid; LABA: Long-acting beta agonist; LAMA: Long-acting muscarinic antagonist; N: Number of participants; NOK: Norwegian krone; OR: Odds ratio; p50: Median; REK: The Regional Committee for Medical and Health Research Ethics; SABA: Short-acting beta agonist; SAMA: Short-acting muscarinic antagonist; SD: Standard deviation

\section{Acknowledgements}

The authors are indebted to Margrete Klemmetsby, Hege Marie Schnelle, Idunn Riisnes, Jan Egil Romestrand, Erik Helgeland, Jan Schille, Lene Svendsen, Tonje Lauvaasvaag, Heike Wiegmann, and Lene Kvamsdal for their contribution in collecting the data for EconCOPD.

\section{Funding}

The EconCOPD-study received funding from Yara Praxair, The Norwegian Heart and Lung Patient Organisation, and AstraZeneca. The funding bodies did not have any role in the design of the study, nor in the collection, analysis, and interpretation of data, nor in writing the manuscript. 


\section{Availability of data and materials}

The datasets used and/or analysed during the current study are available from the corresponding author on reasonable request.

\section{Authors' contributions}

Design, planning and data collection: PB, RN, and AG. Data management and quality control: BJ, ME and RN. Statistical analyses: RN, BJ, and ME. Analysis plan: RN, and BJ. Drafting: ME, RN, and BJ. Revision and approval of drafts: $M E, B J, T M E, A G, P B$, and RN.

\section{Ethics approval and consent to participate}

The Regional Committee for Medical and Health Research Ethics in Western Norway approved the study (REK Vest case number 252.04), and all participants provided written consent.

\section{Consent for publication}

Not applicable as no personal information is provided in the manuscript.

\section{Competing interests}

BJ reports no competing interests.

ME received a research grant from AstraZeneca in November 2015.

TME has received fees from AstraZeneca and Boehringer Ingelheim for speaking at conferences within the last 3 years.

$\mathrm{PB}$ reports no competing interests.

AG reports no competing interests

RN reports grants from Yara Praxair, grants from The Norwegian Heart and Lung Patient Organisation, and grants from AstraZeneca during the conduct of the study; personal fees from AstraZeneca, grants from Boehringer Ingelheim, and grants from GlaxoSmithKline outside the submitted work. He is currently acting as an Associate Editor for BMC Pulmonary Medicine.

\section{Publisher's Note}

Springer Nature remains neutral with regard to jurisdictional claims in published maps and institutional affiliations.

\section{Author details}

'Department of Thoracic Medicine, Haukeland University Hospital, Bergen, Norway. ${ }^{2}$ Department of Clinical Science, University of Bergen, N-5021 Bergen, Norway. ${ }^{3}$ Haukeland, Universitetssjukehus, Laboratoriebygget, Jonas Lies veg 87, 5021 Bergen, Norway.

\section{Received: 20 March 2018 Accepted: 30 November 2018}

\section{Published online: 20 December 2018}

\section{References}

1. World Health Organization. Projections of mortality and causes of death, 2015 and 2030; Available from: http://www.who.int/healthinfo/ global_burden disease/projections/en/. Accessed Feb 2018.

2. Sullivan SD, Ramsey SD, Lee TA. The economic burden of COPD. Chest. 2000;117(2 Suppl):5S-9S

3. Donaldson GC, et al. Relationship between exacerbation frequency and lung function decline in chronic obstructive pulmonary disease. Thorax. 2002;57(10):847-52.

4. Halpin DM, et al. Exacerbation frequency and course of COPD. Int J Chron Obstruct Pulmon Dis. 2012:7:653-61.

5. Seemungal TA, et al. Effect of exacerbation on quality of life in patients with chronic obstructive pulmonary disease. Am J Respir Crit Care Med. 1998; 157(5 Pt 1):1418-22.

6. Thomas $\mathrm{M}$, et al. COPD exacerbation frequency, pharmacotherapy and resource use: an observational study in UK primary care. COPD. 2014; 11(3):300-9.

7. Wedzicha JA, et al. Mechanisms and impact of the frequent exacerbator phenotype in chronic obstructive pulmonary disease. BMC Med. 2013;11:181.

8. Lokke A, et al. Developing COPD: a 25 year follow up study of the general population. Thorax. 2006;61(11):935-9.

9. Schikowski T, et al. Long-term air pollution exposure and living close to busy roads are associated with COPD in women. Respir Res. 2005:6:152.

10. Oxman AD, et al. Occupational dust exposure and chronic obstructive pulmonary disease. A systematic overview of the evidence. Am Rev Respir Dis. 1993;148(1):38-48
11. Sunyer J, et al. Lung function decline, chronic bronchitis, and occupational exposures in young adults. Am J Respir Crit Care Med. 2005:172(9):1139-45.

12. Corrado A, Rossi A. How far is real life from COPD therapy guidelines? An Italian observational study. Respir Med. 2012;106(7):989-97.

13. Visentin $E$, et al. An observation of prescription behaviors and adherence to guidelines in patients with COPD: real world data from October 2012 to September 2014. Curr Med Res Opin. 2016;32(9):1493-502.

14. Lopez-Campos $\mathrm{J}$, et al. Guideline adherence in outpatient clinics for chronic obstructive pulmonary disease: results from a clinical audit. PLoS One. 2016;11(3):e0151896.

15. Sen $\mathrm{E}_{\text {, et }}$ al. Adherence to GOLD guideline treatment recommendations among pulmonologists in Turkey. Int J Chron Obstruct Pulmon Dis. 2015:10:2657-63.

16. Price $D$, et al. Management of COPD in the UK primary-care setting: an analysis of real-life prescribing patterns. Int J Chron Obstruct Pulmon Dis. 2014;9:889-904.

17. Tang CY, et al. Level of adherence to the GOLD strategy document for management of patients admitted to hospital with an acute exacerbation of COPD. Respirology. 2014;19(8):1191-7.

18. Maio $S$, et al. COPD management according to old and new GOLD guidelines: an observational study with Italian general practitioners. Curr Med Res Opin. 2014;30(6):1033-42.

19. Laniado-Laborin $\mathrm{R}$, et al. Subutilization of COPD guidelines in primary care: a pilot study. J Prim Care Community Health. 2013;4(3):172-6.

20. Sarc I, et al. Adherence to treatment guidelines and long-term survival in hospitalized patients with chronic obstructive pulmonary disease. J Eval Clin Pract. 2011;17(4):737-43.

21. Jiang $Y Q$, et al. Impact of adherence to GOLD guidelines on 6-minute walk distance, MRC dyspnea scale score, lung function decline, quality of life, and quality-adjusted life years in a Shanghai suburb. Genet Mol Res. 2015;14(3): 8861-70.

22. de Miguel-Diez J, et al. Inappropriate overuse of inhaled corticosteroids for COPD patients: impact on health costs and health status. Lung. 2011;189(3): 199-206.

23. Global Initiative for Chronic Obstructive Lung Disease (GOLD), GOLD webpage, about us. https://goldcopd.org/about-us/.

24. Lange $P$, et al. The quality of COPD care in general practice in Denmark: the KVASIMODO study. Prim Care Respir J. 2007:16(3):174-81.

25. Roberts CM, et al. European hospital adherence to GOLD recommendations for chronic obstructive pulmonary disease (COPD) exacerbation admissions. Thorax. 2013;68(12):1169-71.

26. Bernd $L$, et al. Determinants of underdiagnosis of COPD in national and international surveys. Chest. 2015;148(4):971-85.

27. Belletti $D$, et al. Results of the CAPPS: COPD--assessment of practice in primary care study. Curr Med Res Opin. 2013:29(8):957-66.

28. Sharif $\mathrm{R}$, et al. Guideline adherence in management of stable chronic obstructive pulmonary disease. Respir Med. 2013;107(7):1046-52.

29. Desalu OO, et al. Guideline-based COPD management in a resource-limited setting - physicians' understanding, adherence and barriers: a crosssectional survey of internal and family medicine hospital-based physicians in Nigeria. Prim Care Respir J. 2013:22(1):79-85.

30. Aisanov Z, et al. Primary care physician perceptions on the diagnosis and management of chronic obstructive pulmonary disease in diverse regions of the world. Int J Chron Obstruct Pulmon Dis. 2012;7:271-82.

31. Perez $X$, et al. Barriers to adherence to COPD guidelines among primary care providers. Respir Med. 2012;106(3):374-81.

32. Nielsen R, Klemmetsby M, Gulsvik A. Economics of COPD: literature review and experiences from field work. Clin Respir J. 2008;2(Suppl 1):104-10.

33. Johannessen $\mathrm{A}$, et al. Implications of reversibility testing on prevalence and risk factors for chronic obstructive pulmonary disease: a community study. Thorax. 2005;60(10):842-7.

34. ATS. Standardization of spirometry, 1994 Update. American Thoracic Society. Am J Respir Crit Care Med. 1995;152:1107-36.

35. Gulsvik A, et al. Expiratory and inspiratory forced vital capacity and one-second forced volume in asymptomatic never-smokers in Norway. Clin Physiol. 2001:21(6):648-60.

36. Charlson ME, et al. A new method of classifying prognostic comorbidity in longitudinal studies: development and validation. J Chronic Dis. 1987; 40(5):373-83

37. Pauwels RA, et al. Global strategy for the diagnosis, management, and prevention of chronic obstructive pulmonary disease. NHLBI/WHO global 
initiative for chronic obstructive lung disease (GOLD) workshop summary. Am J Respir Crit Care Med. 2001;163(5):1256-76.

38. Maddocks M, et al. Physical frailty and pulmonary rehabilitation in COPD: a prospective cohort study. Thorax. 2016;71(11):988-95.

39. McCarthy $B$, et al. Pulmonary rehabilitation for chronic obstructive pulmonary disease. Cochrane Database Syst Rev. 2015;2:CD003793.

40. Sandelowsky $\mathrm{H}$, et al. COPD management by Swedish general practitioners - baseline results of the PRIMAIR study. Scand J Prim Health Care. 2018:1-9.

41. Drivenes E, Ostrem A, Melbye H. Predictors of ICS/LABA prescribing in COPD patients: a study from general practice. BMC Fam Pract. 2014;15:42.

42. Laue J, Reierth E, Melbye H. When should acute exacerbations of COPD be treated with systemic corticosteroids and antibiotics in primary care: a systematic review of current COPD guidelines. NPJ Prim Care Respir Med. 2015;25:15002.

43. Volla TT, Kopperud G. Vedlikeholdsbehandling av kronisk obstruktiv lungesykdom. Tidsskriftet for den norske legeforening; 2008.

44. Medisin D. Myndighetene tar ikke ansvar; 2015.

45. Nielsen R. Costs of chronic obstructive pulmonary disease in a general population. Methodological aspects and longitudinal perspectives (dissertation); 2011.

46. Nielsen R, et al. Excessive costs of COPD in ever-smokers. A longitudinal community study. Respir Med. 2011;105(3):485-93.

Ready to submit your research? Choose BMC and benefit from:

- fast, convenient online submission

- thorough peer review by experienced researchers in your field

- rapid publication on acceptance

- support for research data, including large and complex data types

- gold Open Access which fosters wider collaboration and increased citations

- maximum visibility for your research: over $100 \mathrm{M}$ website views per year

At BMC, research is always in progress.

Learn more biomedcentral.com/submissions 